\title{
Suggestions on increasing the germination seeds of pasture fodder plants
}

\author{
Bakhadir Mirzaev ${ }^{1 *}$, Farmon Mamatov ${ }^{2,3}$, Bakhtiyor Tulaganov ${ }^{1}$, Amir Sadirov $^{1}$, Rustam \\ Khudayqulov $^{1}$, Abbos Bozorboev ${ }^{1}$ \\ ${ }^{1}$ Tashkent Institute of Irrigation and Agricultural Mechanization Engineers, Tashkent, Uzbekistan \\ ${ }^{2}$ Karshi branch of Tashkent Institute of Irrigation and Agricultural Mechanization Engineers, Karshi, \\ Uzbekistan \\ ${ }^{3}$ Karshi Engineering Economic Institute, Karshi, Uzbekistan
}

\begin{abstract}
One of the problems in the seed production of pasture forage plants is low seed germination. Existing pasture improvement technologies and technical means for seed production, harvesting, post-harvest handling, and storage of pasture forage plants are analysed. Suggestions for improving seed germination have been developed: it is advisable to place the seed crops between the forest belts; to improve seed germination, it is necessary to make a preliminary harvest of seed crops with spreading the mass on the stubble; the mechanised collection of seed heaps using a rotary mower with an active heap separator increases the germination rate by reducing mechanical damage to the seeds and enriching the soil with organic matter; the seed sowing process has a positive effect on the germination rate of the seed produced, in addition to reducing cleaning costs.
\end{abstract}

\section{Introduction}

In the last decade, extensive research has been carried out worldwide on the development of less energy-intensive and more productive tillage and combination machines that perform several operations in a single machine pass, [1-25] as well as seeding machines [26-29] and machines for harvesting and processing agricultural products [30,31].

The vegetation of natural desert and semi-desert (arid) pastures of Uzbekistan, occupying substantial (about 20 million hectares) territory, represents a feed base of astrakhan husbandry, and in general, desert-pasture livestock of the republic. The specificity of the industry is the year-round keeping of animals in the past of feed pastures. Despite the low productivity of fodder plants of natural pastures (2-4 centners per hectare) and strong fluctuations on years and seasons of the year, which determines the risky nature of the industry, generally, it is recognized that they are the cheapest sources of feed.

At the same time, the flora of the arid zone is a relatively fragile ecosystem. Climate changes of the last decades, irrational use of pasture resources (cutting bushes and shrubs for fuel and animal feed for winter, not following rules of pasture, technogenic impacts,

\footnotetext{
* Corresponding author: bahadir.mirzaev@bk.ru
} 
overloading in feeding, and others) are associated not only with a decrease in productivity of fodder plants but also with the extinction of separate types of biodiversity.

Moreover, irrational use of pastures is fraught with their degradation [32-34]. It is obvious that the paramount objective of the stable development of arid-pasture livestock is ensuring the productivity of pastures by restoring degraded, improving low-yielding, and narrowly seasonal pastures. The successful solution of the set objective taking into account large volumes of work, depends on the use of effective mechanized technologies and complexes of machines, as well as the provision of high-quality seeds of perspective pasture of fodder plants.

In previous years of joint research by the Scientific Research Institute of Agricultural Mechanization (SRIAM) and Scientific Research Institute of Astrakhan Husbandry and Desert Ecology (SRIAHDE), the advanced technology has developed of improving pasture based on the creation of shelterbelts.

For its base, there has been accepted the technology of improving pasture saxaul strips, which has several positive features.

Thus, saxaul strips:

- wind speed is reduced to 5-2.0 times, snow is delayed, and soil is protected from drying out;

- without additional intervention is contributed to the increase of feed productivity of pasture from the leeward side of strips to $20 \%$ at a distance of 100 meters or more [32-34]; - yield of feed-in strips itself is increased by 2-3 times.

\section{Methods}

According to advanced technology, strips are created from a mixture of saxaul, shrubs, and herbs instead of pure saxaul. The method of selecting plants for the concrete condition is ensured the expansion of seasonality and increase of pasture productivity. Plants rationally use ecological niches.

Shelterbelts themselves are laid on the base of soil cultivation with narrow (up to $25 \mathrm{sm}$ ) strips. This provides technologies with additional energy-saving and environmental features, as well as substantial seed savings.

Extreme climatic and soil conditions of pastures: high temperatures in summer, dry winds, moisture deficiency, and poor soil nutrients cause low germination of cultivated seeds of desert-pasture fodder plants. Due to the seriousness of the problem, many researchers have studied the matters of germination seed. The review materials and literary sources (Table 1) indicate incomparably low germination of seeds of desert fodder plants compared with seeds of crops cultivated in the irrigated zone.

Table 1. Germination seed of fodder plants in arid pastures

\begin{tabular}{|l|c|c|}
\hline Plant & \multicolumn{2}{|c|}{ Germination $\%$} \\
\hline Saxaul & Laboratory & Field \\
\hline Chogon & $18.0-92.5$ & $1.0-28.8$ \\
\hline Isen & - & $0.1-38.0$ \\
\hline Keireuk & from 5.0-10.0 up to 80.0-90.0 & $0.05-17.0$ \\
\hline Sagerush & $20.0-60.0$ up to 80.0-90.0 & $0.5-5.0$ \\
\hline Borzhok & $13.0-47.0$ & Up to 10.0 \\
\hline Kandym & $60.0-86.0$ & 26.3 \\
\hline Annual hodgepodge & up to 50.0 after stratification & $11.0-13.0$ \\
& $\begin{array}{c}\text { danashur-14.6 } \\
\text { haridandan-5.3 }\end{array}$ & $\begin{array}{c}\text { danashur- } 0.6-10.0 \\
\text { haridandan- } 0.3-1.0\end{array}$ \\
\hline
\end{tabular}




\section{Results and Discussion}

Z.Sh.Shamsutdinov found that the laboratory germination of seeds of pasture plants ranges from $20-98 \%$. At the same time, their field germination is rather low - from $0.5-3.0$ to $20.0 \%[33,34]$.

Thus, along with the need to produce a substantial volume of seeds of pasture fodder plants, calculated with tens of thousands of tons, a not less important problem remains the question of increasing their germination. This is a complex problem, which covers issues of high-performance, mechanized, environmental, resource-saving technologies and complexes of machines on seed production, harvesting, post-harvest processing, storage of rational use of them for restoring degraded and improvement of low-yielding and narrowly seasonal pastures.

Practically all operations of the technological process of seed production and technical means of their realization influence the indicator. A particular interest arises questions of reducing stress effects of soil and climatic condition.

As it has already been noted, the productivity of aboriginal vegetation in areas conterminal to saxaul strips increases significantly. It seems equally true for shelterbelts. The productivity of pastures between shelterbelts is increased due to a favourable microclimate and better moisture supply. These moments (microclimate and better moisture supply) are significant factors, predetermining the expediency of load seed sowing of fodder crops in the interval between shelterbelts.

For growing seeds of increased germination, the adhesion of the agrotechnical requirements of each operation of technological process and the choice of plot is also required. The plots should be characterized by the absence of stones and a high content of weed productively vegetation. It is desirable the plots with a flat relief, allowing to use high productive agricultural machines.

Seedy sowings on the reason for nature conservation lay on strip plowing. The main agricultural background is pure steam, which accumulates moisture, helps to obtain friendly seedlings, the rapid growth, and development of plants.

Seeds of desert fodder plants need small placement because the soil is leveled before sowing. In practice, pre-sowing work, as a rule, is limited by shorting and harrowing. To do this as a small object (rails, concrete poles, wooden beams, etc.), ordinary tooth harrows are clung. With this method, there are high expenses of manual labor and time for loading and unloading works during transportation to the workplace and preparing work-mentioned heavy objects. The expense of considerable time is the reason for the loss of optimal agro technical sowing dates. It is especially noted, these shortcomings are manifested in the arid zone due to a shortage of labor resources, large spaces, determining far transportation distances. Therefore, here for seed production is preferable a small eliminating need for loading and unloading. By Joint Stock Organization mounted Head Special Constructive Bureau (HSCB-Agromash) there has been developed less original (by transportation is plunging, at work-trailed) constructions (Figure 1). 


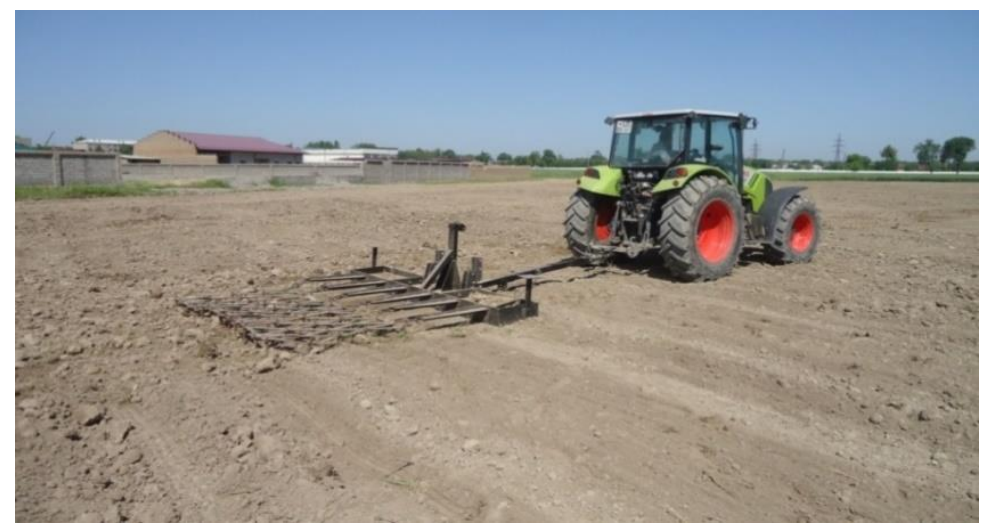

Fig. 1. Small at work

To cultivate high germination seeds and timely sowing, it is important that the load seeds are planted at the optimum depth. Seeds of a desert - pasture fodder plants need a shallow (not deep) loading in soil. Thus, researchers note that the cultivation of thistle, black saxaul, and keireuk seeds to the depth of $0.5-1.0 \mathrm{~cm}$ significantly increases their field germination [34]. In natural pasture cenosis, the storage of species, their change occurs due to self-sowing without human intervention, that is, without special seed placement. Wind, soil erosion, animals, etc., are those natural forces that contribute to their conservation, reproduction, change. All this happens spontaneously.

The reasonable intervention into this process will contribute to a more efficient economic assimilation of pastures and a more appropriate direction for the development of flora. Our experiments have shown that the best way required is not seeding; deep placement is provided while sowing seeds on surface soil in furrows with a depth of 3,0-4,0 the followed by a packing roller. While packing, the main part of seeds is embedded in soil due to the crushing of soil lumps and soil displacement. The rest of the seeds remain pressed to the surface of the soil. Subsequently, they are self-sealed due to wind and draught. By this, the small placement of seeds of desert fodder plants is provided by required agricultural technology. A similar placement method has been adopted in construct or combine aggregate for the improvement of pastures and a mounted seeder for planting seed crops, developed at Head Special Constructive Bureau Agromash (HSCB-Agromash).

A good effect on increasing seed germination is provided by treating seed heap before sowing with ultraviolet rays of the UV device. According to the Scientific Research Institute of Astrakhan Husbandry and Desert Ecology (SRIAHDE), in experiments conducted at Nuratin experimental length stationary of the institute, the average number of planting in the length of per 10 meters in cultivated UVD seeds was $56.9 \pm 0,03$, versus $39,0 \pm 0,2$ without cultivation. The cultivation of seeds of the UVD at Head Special Constructive Buroau Agromash has been produced, which is connected to a household electrical network and can be used to cultivate seeds of any crops. Joint experience at Head Special Constructive Bureau Agromash and Scientific Research Institute of Astrakhan Husbandry and Desert Ecology (SRIAHDE) has also established the beneficial effect of Ultraviolet radiation device (UVD) to the seedling survival and their development. Considering the effectiveness of measure for processing of production crops at Head Special Constructive Bureau Agromash CSR-2,1 cultivator was made with a UVD attachment, mounted in front of the tractor spar (Fig. 2). 
Device installation diagram. Advancement of UVD
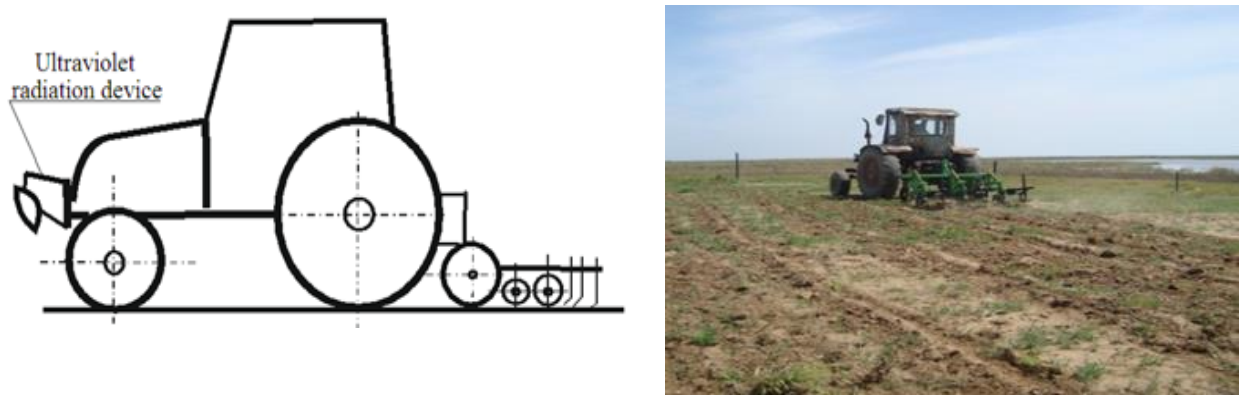

Fig. 2. Cultivator CSR-2.1 with a device for UVD

The seeds of desert fodder plants are collected, as a rule, by hand in the form of seed heaps containing up to $60 \%$ of organic litter. Manual harvesting is inefficient, laborious, and does not meet the needs of production in seed material. Considering the actuality of the problem, studies have previously been conducted on the mechanization of seed harvesting by direct combining and in a separate way using choppers.

The disadvantages of these methods are damage of seeds in threshing part of combine and in grinding drum of pick-up grinder, which reduce the germination of seeds. It is more advisable to use the development of ISESH on the usage of converted seedbed mowers for harvesting seed heaps with the ejection of stem part of the testes on stubble despite some increased seed losses.

Analyzing the methods of mechanized harvesting of seed heap from the point of view of increasing seed germination, it can be stated the perspectivity of mowing seed mass with a scattering of stem part on stubble. Long-term practice of this method will contribute to the growth of organic matter in the soil, which in turn will contribute to better development of seed crops and, as a result, increase the germination rate of cultivated seeds. At present, Head Special Constructive Bureau Agromash has been developing a special seed collector for desert pasture fodder plants with an active heap separator and ejection of stem part into stubble (Figure 3).

The machine consists of the rotary cutting device 1 with hanging knives 2 , a deflector 3 , a reflector 4 , a separator with drums 5 , a pallet 6 , a hopper with a bottom 7 , and an unloading valve 8 . According to the technological scheme, beveled and partially crushed mass, being reflected from the reflector, falls onto the beginning of an inclined separator, drums of which move it to the exit. In the process of moving from mass, seeds and small litter are released and, by passing through the separator falling into the hopper. A large fraction leaving the separator is scattered on swath.

In the direction of increasing seed germination of desert fodder plants, the issue of seed heap cleaning should be reviewed. It seems that the desire for a high degree of purification of seeds, if not granulated, it doesn't make any practical sense. Moreover, cleaning them is very complicated. The results of researchers show that it requires the use of complicated equipment with the usage of mechanical and pneumatic principles. On the other hand, the soil is poor in humus. It seems rational to sow seed heap in such conditions, from which only large fractions that violate the sowing process are removed. Seed heap can be clogged with organic impurities as much as necessary if it does not contain large litter that interferes with the sowing process. In addition, the organic litter will create a favorable microclimate for young seedlings. With this question, there is no need to create a complex cleaner. It is enough to develop a heap enrichment agent that removes only large litter that interferes with the sowing process. The long-term practice of sowing seeds with an enriched seed heap will also increase the germination capacity of cultivated seeds. 


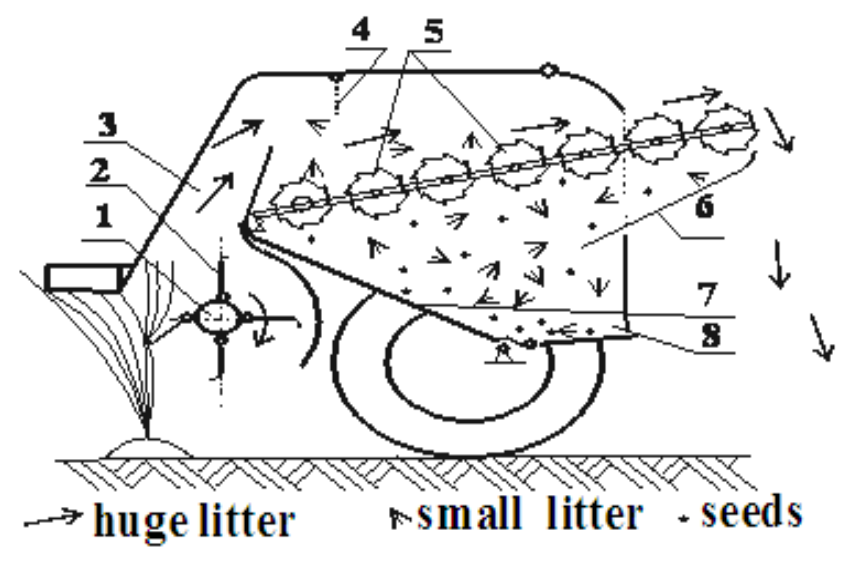

Fig. 3. Seed picker diagram

One of the conditions for increasing the germination of cultivated seeds may be early partial mowing (semi-mowing) of seed crops. Our experiments noted that early mowing (semi-mowing) of seed crops has a beneficial effect on plant development. After mowing, the best regrowth of plants was noticed. Plants are obtained more powerful, and seeds are obtained with better germination. Spreading of mowed mass of the preliminary mowing (semi-mowing) into the swath will also contribute to the enrichment of soil with organic matter, which subsequently will have a beneficial effect on seed germination.

\section{Conclusions}

In conclusion, by summarizing the ideas given above, it can mention the following suggestions that contribute to increasing the germination of seeds:

1. It is advisable to place seed crops in the interval between shelterbelts;

2. Under testes, it is necessary to choose land with a smooth relief, which is not clogged with weed vegetation;

3. Seed crops should be planted in a clean pair;

4. A positive effect on germination seed indicator is provided by the cultivation of seed heap and seedlings of the UVD;

5. Germination seed positively affects preliminary mowing (semi-mowing) of seed crops with spreading the mass on the stubble;

6. Mechanized collection of seed heap by a rotary mower with an active heap separator helps to increase the germination indicator by reducing mechanical damage to seeds and soil enrichment with organic matter;

7. Sowing seed heaps, apart from reducing cleaning costs, positively affects the germination indicator of produced seeds.

8. The solutions presented in the article will significantly increase the seed germination indicator and, thereby, contribute to solving the problem of ensuring the restoration of degraded and improving low-yielding and narrowly seasonal pastures with high-quality sowing material. At the same time, these measures contribute to the reduction of the cost of production of seeds of pasture plants. 


\section{References}

1. F. Mamatov, I. Ergashev, B. Mirzaev, X. Pardaev, and D. Chorieva, J. Phys. Conf. Ser. 1779, 12002 (2021)

2. F. Mamatov, I. Ergashev, S. Ochilov, and X. Pardaev, J. Adv. Res. Dyn. Control Syst. 12, 2154 (2020)

3. Z. Uzakov, F. Mamatov, and O. Begulov, in 2019 Int. Conf. Inf. Sci. Commun. Technol. (2019), pp. 1-5

4. B. Mirzaev, F. Mamatov, and O. Tursunov, in E3S Web Conf. (2019)

5. U. Kodirov, N. Aldoshin, S. Ubaydullayev, E. Sharipov, Z. Muqimov, and B. Tulaganov, \{IOP $\}$ Conf. Ser. Mater. Sci. Eng. 883, 12143 (2020)

6. K. Ravshanov, K. Fayzullaev, I. Ismoilov, D. Irgashev, S. Mamatov, and S. Mardonov, \{IOP $\}$ Conf. Ser. Mater. Sci. Eng. 883, 12138 (2020)

7. K. Ravshanov, L. Babajanov, S. Kuziev, N. Rashidov, and S. Kurbanov, $\{$ IOP $\}$ Conf. Ser. Mater. Sci. Eng. 883, 12139 (2020)

8. D. Chuyanov, G. Shodmonov, I. Avazov, N. Rashidov, and S. Ochilov, $\{$ IOP $\}$ Conf. Ser. Mater. Sci. Eng. 883, 12122 (2020)

9. F. Mamatov, B. Mirzaev, and I. Avazov, Agrotehnicheskie Osnovy Sozdanija Protivojerozionnyh Vlagosberegajushhih Tehnicheskih Sredstv Obrabotki Pochvy v Uslovijah Uzbekistana (2014)

10. F. Mamatov and B. Mirzaev, Eur. Appl. Sci. 4, 71 (2014)

11. J. Lobachevskij, F. Mamatov, and I. Jergashev, Hlopok 35 (1991)

12. B. J. Ahmedov, B. S. Mirzaev, F. M. Mamatov, D. A. Khodzhaev, and M. K. Julliev, in InterCarto, InterGIS (2020), pp. 547-560

13. N. Aldoshin, F. Mamatov, I. Ismailov, and G. Ergashov, in 19th Int. Sci. Conf. Eng. Rural Dev. (2020), pp. 767-772

14. F. Mamatov, B. Mirzaev, O. Tursunov, S. Ochilov, and D. Chorieva, in IOP Conf. Ser. Earth Environ. Sci. (2020)

15. U. Umurzakov, F. Mamatov, N. Aldoshin, and B. Mirzaev, in IOP Conf. Ser. Earth Environ. Sci. (2020)

16. F. Mamatov, N. Aldoshin, B. Mirzaev, H. Ravshanov, S. Kurbanov, and N. Rashidov, \{IOP $\}$ Conf. Ser. Mater. Sci. Eng. 1030, 12135 (2021)

17. K. D. Astanakulov, G. G. Fozilov, B. K. Kodirov, I. Khudaev, K. Shermukhamedov, and F. Umarova, in IOP Conf. Ser. Earth Environ. Sci. (2020)

18. K. D. Astanakulov, G. G. Fozilov, N. M. Kurbanov, B. S. Adashev, and S. A. Boyturayev, in IOP Conf. Ser. Earth Environ. Sci. (2020)

19. U. Umurzakov, B. Mirzaev, F. Mamatov, H. Ravshanov, and S. Kurbonov, in IOP Conf. Ser. Earth Environ. Sci. (2019)

20. B. Mirzaev, F. Mamatov, D. Chuyanov, H. Ravshanov, G. Shodmonov, R. Tavashov, and X. Fayzullayev, in IOP Conf. Ser. Earth Environ. Sci. (2019)

21. B. Mirzaev, F. Mamatov, I. Ergashev, H. Ravshanov, S. Mirzaxodjaev, S. Kurbanov, U. Kodirov, and G. Ergashev, in E3S Web Conf. (2019)

22. F. Mamatov, B. Mirzaev, Z. Batirov, S. Toshtemirov, O. Tursunov, and L. Bobojonov, in IOP Conf. Ser. Mater. Sci. Eng. (2020)

23. B. Mirzaev, F. Mamatov, I. Avazov, and S. Mardonov, in E3S Web Conf. (2019)

24. B. Mirzayev, F. Mamatov, N. Aldoshin, and M. Amonov, in TAE 2019 - Proceeding 7th Int. Conf. Trends Agric. Eng. 2019 (2019), pp. 391-395

25. B. Mirzaev, F. Mamatov, I. Ergashev, Y. Islomov, B. Toshtemirov, and O. Tursunov, Procedia Environ. Sci. Eng. Manag. 6, 395 (2019)

26. F. Mamatov, B. Mirzaev, S. Mirzahodzhaev, Z. Uzakov, and D. Choriyeva, $\{$ IOP $\}$ Conf. Ser. Mater. Sci. Eng. 1030, 12164 (2021) 
27. F. Mamatov, B. Mirzaev, M. Shoumarova, P. Berdimuratov, and D. Khodzhaev, Int. J. Eng. Adv. Technol. 9, 4824 (2019)

28. F. Mamatov, B. Mirzaev, P. Berdimuratov, K. Turkmenov, L. Muratov, and G. Eshchanova, in IOP Conf. Ser. Mater. Sci. Eng. (2020)

29. N. Aldoshin, O. Didmanidze, B. Mirzayev, and F. Mamatov, in TAE 2019 Proceeding 7th Int. Conf. Trends Agric. Eng. 2019 (2019), pp. 20-25

30. F. Mamatov, E. Eshdavlatov, and A. Suyunov, J. Adv. Res. Dyn. Control Syst. 12, 2195 (2020)

31. F. Mamatov, E. Eshdavlatov, and A. Suyunov, J. Adv. Res. Dyn. Control Syst. 12, $2016(2020)$

32. A. Rafikov, Bull. State Comm. Sci. Technol. Repub. Uzb. 48 (1997)

33. Z. Shamsutdinov, Creation of Long-Term Pastures in the Arid Zone of Central Asia (Tashkent, 1975)

34. Z. Shamsutdinov, S. Ubaydullaev, N. Shamsutdinov, B. Mirzaev, F. Mamatov, and N. Chorshabiyev, in IOP Conf. Ser. Earth Environ. Sci. (2020) 